\title{
Pembuatan Tungku Induksi Sederhana
}

\author{
Syahbardia $^{1)}$, Herman Somantri ${ }^{2)}$, \& Aldi Suryaman \\ 1) Teknik Mesin,Universitas Diponegoro Telp:024-7460024, Fax: 024-7460027, \\ ${ }^{2)}$ Teknik Mesin, Universitas Pasundan Telp:022-2019435, Fax022-2019329, \\ Website:www.undip.ac.id, E-mail: syahbardia@student.undip.ac.id
}

\begin{abstract}
Abstrak - Tungku induksi merupakan salah satu alat untuk proses pemanasan logam yang saat ini banyak digunakan di lingkungan industri, yang mana alat ini digunakan untuk melebur atau memanaskan logam. Maka dari itu untuk mengikuti perkembangan zaman dan untuk mempelajari kinerja tungku induksi agar dapat memahami dan mengetahui prinsip kerja dari pemanas induksi maka dari itu dilakukan penelitian pemanas atau tungku induksi sederhana.

Metodologi penelitian dimulai dengan : perancangan yaitu, pemilihan sistem pemanas induksi sederhana, menentukan komponen-komponen yang digunakan, proses pembuatannya dan melakukan pengujian pada pemanas induksi sederhana. Dalam proses pengujian dilakukan dua tahap pengujian yaitu proses pengamatan visual yang bertujuan untuk mengetahui apakah komponen pemanas induksi bekerja sesuai dengan yang diinginkan, lalu tahap selanjutnya dilakukan pengujian prestasi,berupa pengukuran untuk mengetahui besar daya yang digunakan dan besar pemanasan yang dihasilkan pada logam uji. Pembuatan pemanas induksi ini menghasilkan alat yang mampu memanaskan logam mencapai suhu $465^{\circ} \mathrm{C}$ selama 10 menit dengan nilai kalor yang dihasilkan sebesar 12192,3J dengan efisiensi thermal sebesar $12.7 \%$.
\end{abstract}

Kata kunci: Tungku, induksi

\section{Pendahuluan}

Pemanasan induksi ditemukan oleh Michael Faraday pada tahun 1831, dimana fenomena pemanasan induksi terjadi ketika suatu logam yang memiliki sifat kemagnetan terkena gelombang elektromagnetik dan akan menimbulkan induksi panas. Seiring perkembangan zaman, penemuan ini semakin berkembang dan dapat dimanfaatkan sebagai dasar dari pembuatan pemanas induksi menggunakan energi listrik yang hasilnya memiliki efisiensi cukup baik dan lebih ramah lingkungan. Kini penemuan ini sering digunakan di industri peleburan logam, industri yang berkaitan dengan proses perlakuan panas pada logam dan kompor untuk rumah tangga.

\section{Dasar Teori}

Pemanas induksi adalah alat yang memanfaatkan timbulnya panas pada logam ferro yang terkena induksi medan magnet, hal ini disebabkan karena pada logam timbul arus eddy yang arahnya melingkar melingkupi medan magnet yang terjadi arus ,akibat dari interaksi induksi magnet yang menimbulkan fluks magnetik yang menembus logam, sehingga menyebabkan panas pada logam. [1].

$$
\left.P=\frac{\pi^{2} B_{p}^{2} d^{2} f^{2}}{6 k \rho D}\right] .
$$

\section{Metodologi Penelitian}

Secara umum metodologi penelitian yang dilakukan ada tiga tahap yaitu:Perancangan, pembuatan dan pengujian.

3.1.Perancangan

A. Kriteria rancangan

Pada pemanas induksi harus memiliki bentuk yang kompak, menggunakan komponen yang banyak dipasaran dan mudah pembuatannya.

\section{B. Alternatif sistem}

Pada pemanas induksi dibutuhkan rangkaian inverter sebagai rangkaian pengubah tegangan DC menjadi AC. Ada beberapa alternatif desain rangkaian pemanas induksi yaitu:

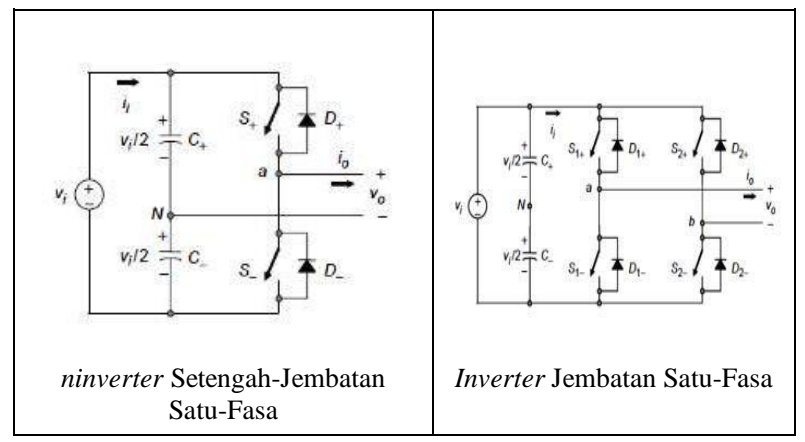




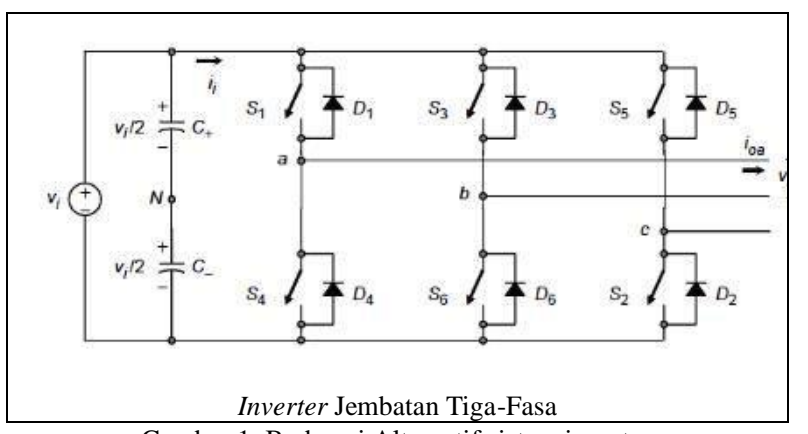

Gambar 1 Berbagai Alternatif sistem inverter

Dari alternatif desain, dipilih rangkaian inverter setengah jembatan satu fasa. Pemilihan desain rangkaian ini ditentukan karena pada proses pembuatannya mudah dan tidak, memerlukan komponen aktif yang banyak dan faktor kegagalan dari pembuatan pemanas induksi lebih kecil dibandingkan dengan rangkaian lainnya.

\section{Pemilihan Komponen Utama Inverter}

Pada Pada pembuatan inverter dibutuhkan beberapa komponen aktif yang berkerja sebagai saklar atau switch yang fungsinya sebagai pembangkit sinyal sinus. Berikut beberapa alternatif dari komponen aktif yang akan digunakan sebagai komponen utama inverter.

\begin{tabular}{l} 
Tabel 1 Berbagai komponen utama inverter \\
\hline Nama komponen \\
\hline IGBT transistor \\
\hline MOSFET transistor \\
\hline Bipolar transistor \\
\hline SCRs \\
\hline GTO Thyristor \\
\hline
\end{tabular}

Dari daftar komponen utama inverter di tabel dipilih komponen MOSFET sebagai komponen pengsakelaran (switch) dikarenakan komponen tersebut memiliki response time yang tinggi, mempunyai impedansi input yang tinggi beberapa Mega Ohm dan mudah didapatkan. Secara ideal MOSFET bekerja sebagai switch yang tertutup bila dalam keadaan jenuh dan sebagai switch yang terbuka bila dalam keadaan terputus.

\section{Catu Daya}

Catu daya terdiri dari rangkaian penyearah arus listrik AC menjadi DC. Dimana komponennya terdiri dari trafo, dioda dan kapasitor.

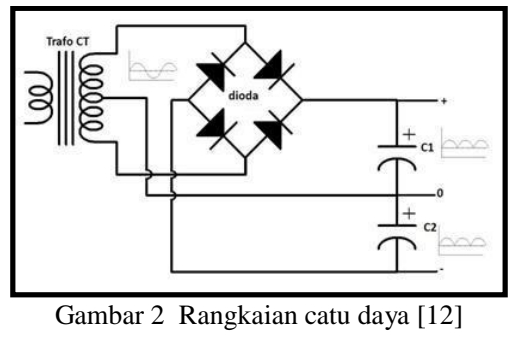

\section{E. Rangkaian inverter frekuensi tinggi}

Rangkaian inverter frekuensi tinggi adalah suatu rangkaian elektonika yang berfungsi untuk merubah arus listik DC menjadi AC frekuensi tinggi. Rangkaian ini terdiri dari
MOSFET, resistor, dioda dan induktor sebagai komponen utamanya.

R3 dan R4 adalah resistor dengan nilai tahanan masingmasing $470 \Omega$ dan daya $5 \mathrm{~W}$ Besarnya tahanan menentukan kecepatan MOSFET menyala. Untuk itu nilai tahanan sebaiknya kecil sehingga kecepatan MOSFET cukup tinggi namun juga tidak terlalu rendah sehingga dapat tereliminasi oleh dioda pada saat MOSFET yang lain dalam posisi on.

Dioda D1 dan D2 dipakai untuk mengosongkan gate MOSFET. Untuk itu dipakai dioda dengan forward voltage drop rendah sehingga gate dapat benar-benar kosong dan MOSFET dapat sepenuhnya off ketika yang lain on. Dioda Schottky dapat dipilih karena memiliki voltage drop yang rendah $(12 \mathrm{~V})$ dan kecepatan tinggi. Tegangan yang diizinkan pada dioda harus cukup untuk mengantisipasi kenaikan tegangan pada sirkuit resonansi.

Transistor $\mathrm{Q}_{1}$ dan $\mathrm{Q}_{2}$ dengan spesifikasi IRFP250 dengan I $\max =30 \mathrm{~A}$ dan $\mathrm{V} \max =200 \mathrm{~V}$ dan dipasang pada heatsink untuk mencegah kerusakan akibat kenaikan temperatur yang tinggi. MOSFET dipilih dengan tahanan drain yang rendah dan response time yang tinggi

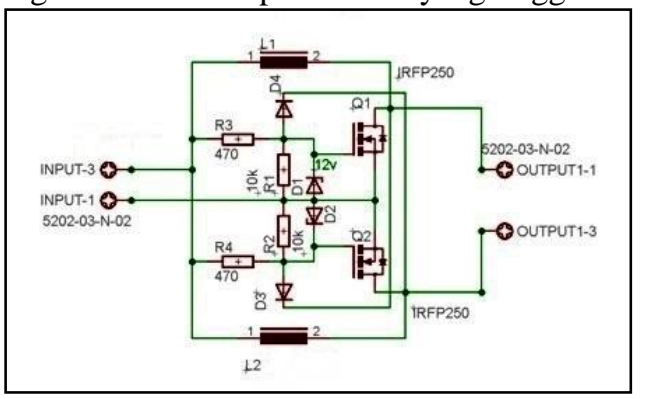

Gambar 3 Rangkaian Inverter Frekuensi Tinggi

\section{F. Kapasitor bank}

Pemanas induksi ini dilengkapi dengan rangkaian kapasitor bank sebagai rangkaian yang berfungsi untuk meperbaiki faktor daya dan sebagai filter osilasi yang berfungsi untuk menghasilkan gelombang sinus. Rangkaian kapasitor bank disusun secara paralel agar nilai kapasitor totalnya berupa penjumlahan dari semua nilai kapasitor yang disusun paralel tersebut. Rangkaian ini menggunakan kapasitor dengan nilai $470 \mu \mathrm{F}, 275 \mathrm{~V}$ dirangkai secara paralel sebanyak 12 buah menghasilkan nilai kapasitor sebesar $5640 \mu \mathrm{F}$.

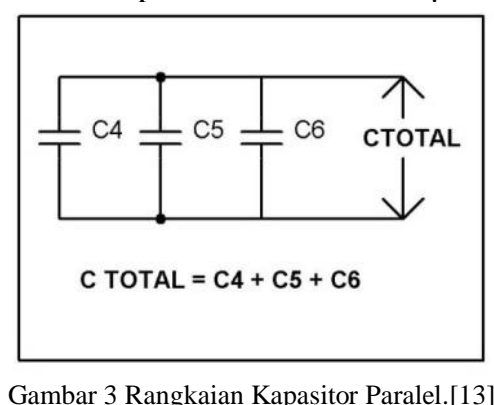

\section{G. Kumparan kerja}

Kumparan kerja berfungsi merubah energi listrik menjadi medan magnet yang besarnya berubah-ubah berdasaran beban yang ada di dalam kumparan kerja yang akan membangkitkan arus eddy yang akan memanaskan logam. 
Kumparan terbuat dari pipa kapiler yang diameter $3 \mathrm{~mm}$. Diameter kumparan $100 \mathrm{~mm}$ dengan panjang $50 \mathrm{~mm}$ yang dilapisi oleh selang tahan panas agar tidak terjadi kontak terhadap benda kerja yang akan dipanaskan. Pada pipa kapiler dialirkan air sebagai media pembuang kalor yang ada di pipa yang bertujuan agar panas yang terjadi pada pipa tidak merusak komponen pemanas induksi tersebut.

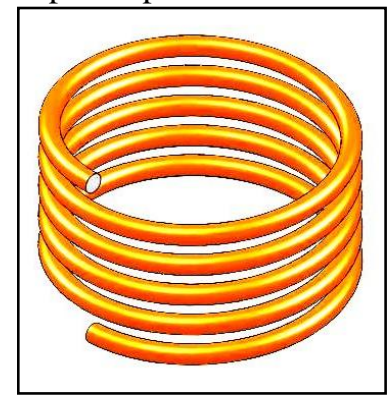

Gambar 4 Kumparan kerja

\subsection{Proses pembuatan}

Berikut ini adalah langkah-langkah proses pembuatan pemanas induksi

\section{A. Pembuatan Catu Daya}

Siapkan komponen-komponen yang akan digunakan yang terdiri dari trafo CT, heat sink, dioda bridge, kapasitor, PCB catu daya, rakit komponen-komponen tersebut dan solder semua komponen hingga terhubung satu sama lain sesuai rangkaiannnya. Untuk PCB catu daya, tidak dibuat pada software eagle dikarenakan telah tersedia dipasaran.

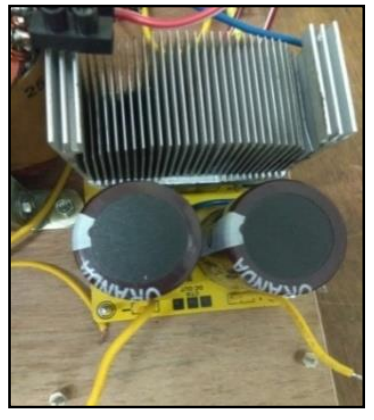

Gambar 5 Catu daya

\section{B. Rangkaian inverter frekuensi tinggi}

Proses pembuatan rangkaian inverter frekuensi tinggi diawali dari pembuatan PCB menggunakan software eagle, digunakan untuk merancang PCB.

Pada pembuatan rangkaian inverter diawali pembuatan skematik rangkaiannya dan skematik komponen yang digunakan seperti gambar dibawah.

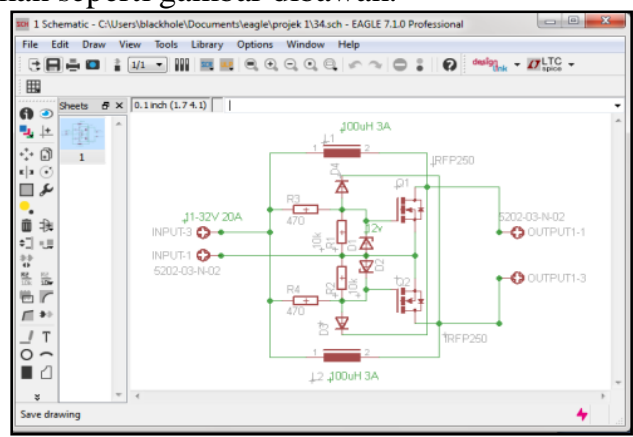

Gambar 6 Skematik Rangkaian pada Eagle.
Setelah pembuatan skematik rangkaian, lalu dilanjutkan dengan penyusunan komponen dan pembuatan jalur-jalur pada PCB seperti pada gambar selanjutnya.

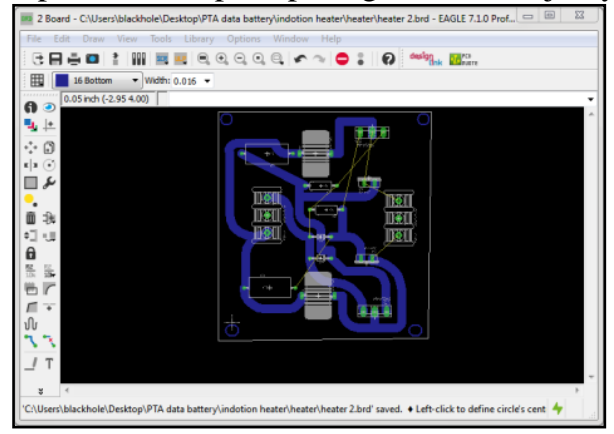

Gambar 7 Desain PCB Pada Eagle

Setelah rangkaian PCB dibuat menggunakan software eagle rangkaian dicetak menjadi PCB. Proses pencetakan PCB menggunakan jasa percetakan PCB. Setalah PCB dibuat, PCB dirakit dengan komponen-komponen sesuai dengan rangkaian yang telah dicetak pada PCB dan di solder hingga terhubung satu sama lain seperti pada gambar.

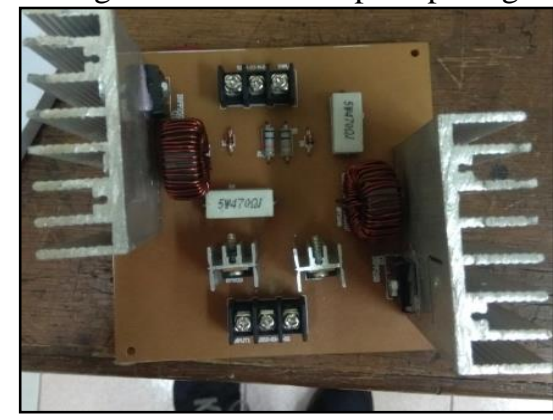

Gambar 8 Rangkaian inverter

\section{Kapasitor bank}

Pada pembuatan kapasitor bank digunakan PCB yang berlubang-lubang dirangkai secara paralel lalu disolder hinga terhubung satu sama lain.

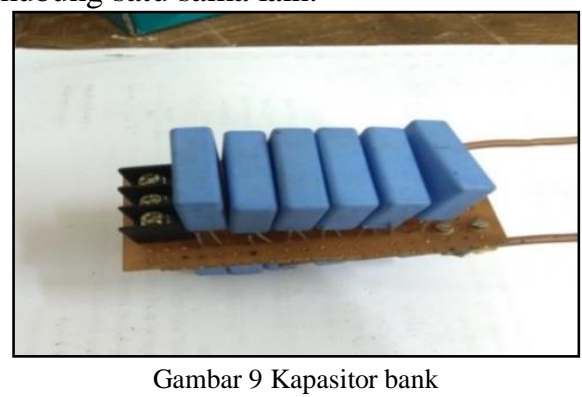

\section{Pembuatan kumparan kerja}

Kumparan kerja dibuat menggunakan pipa kapiler tembaga berdiameter $3 \mathrm{~mm}$ dibentuk seperti pegas melingkar dengan tinggi $50 \mathrm{~mm}$ dan diameter kumparan $100 \mathrm{~mm}$ lalu dibungkus dengan selang tahan panas. Pipa kapiler ini dialiri air menggunakan pompa DC $12 \mathrm{~V}$ menggunakan selang yang berfungsi untuk mendinginkan pipa kapiler yang panas akibat efek harmonik (gangguan yang terjadi pada sistem distribusi tenaga listrik akibat terjadinya distorsi gelombang arus dan tegangan dan menghasilkan panas) pada pipa kapiler. 


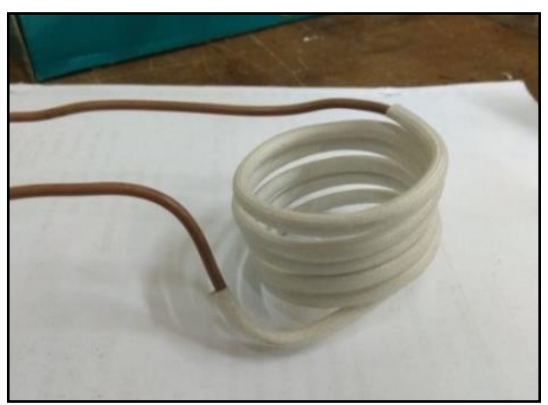

Gambar 10 Kumparan kerja induksi

\section{E. Perakitan}

Pada proses perakitan perangkat-perangkat tersebut dirakit dan dihubungkan satu sama lain menggunakan kabel hingga terhubung seperti pada gambar di bawah ini.

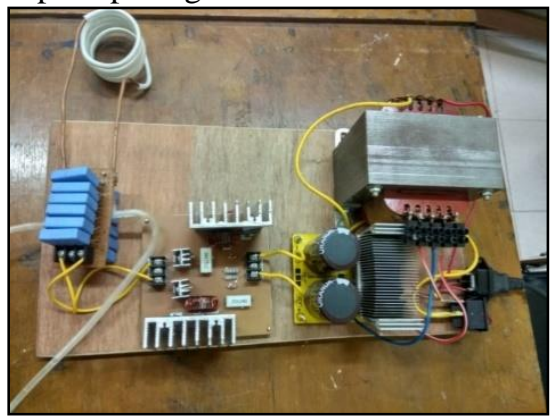

Gambar 11 Pemanas induksi sederhama

\subsection{Pengamatan dan Pengukuran}

\section{A. Pengujian}

Setelah alat selesai dirakit maka dilakukan pengujian untuk mendapatkan data yang selanjutnya akan dianalisis, adapun instalasi alat uji coba dapat dilihat pada Gambar 12. Pada instalasi alat uji coba pemanas induksi ini dipasangkan sebuah pendingin berupa pompa DC yang mengalirkan air ke saluran pipa kapiler menggunakan selang yang bertujuan untuk mendinginkan kumparan kerja agar tidak terjadi kenaikan suhu yang dapat merusak pemanas induksi. Selain pendiginan air ditambahkan sebuah kipas yang berfungsi untuk mendinginkan komponen-komponen pada rangkaian pemanas induksi.

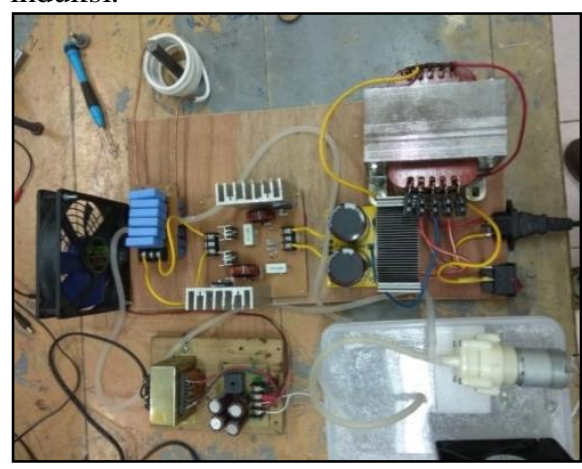

Gambar 12 Instalasi Pengujian

Pengujian pemanas induksi dilakukan secara dua tahap, pengujian berupa pengamatan visual dan pengukuran. Pengujian berupa pengamatan visual bertujuan mengetahui apakah alat dapat berkerja dengan baik. Pengujian berupa pengukuran bertujuan mengetahui tegangan, arus, frekuensi dan temperatur yang dihasilkan dari pemanas induksi.

\section{B. Pengamatan Visual}

Pengujian berupa pengamatan visual dilakukan untuk mengetahui apakah alat tersebut dapat berkerja dan mampu memanaskan logam uji. Untuk pengamatan visual, logam uji yang digunakan berupa baut berdiameter $3 \mathrm{~mm}$ dan panjang $5 \mathrm{~mm}$, baut tersebut dipanaskan dan dapat dilihat di gambar 4.10 baut tersebut memerah. Pada pengamatan ini baut memerah hanya pada pusat gelombang elektromagnetik yang berada pada titik tengah dari kumparan.

Pengamatan visual ini bertujuan untuk mengetahui apakah pemanas induksi dapat berkerja dengan baik dan pada saat berkerja tidak terjadi kerusakan pada komponen yang terpasang pada pemanas induksi sebelum dilakukan proses pengukuran.

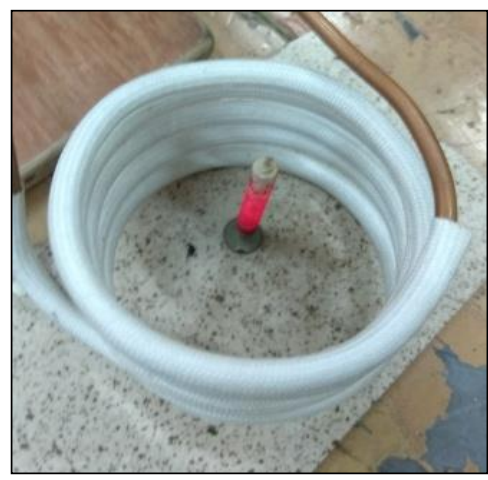

Gambar 13 Logam sample yang memanas

\section{Pengukuran}

Pengukuran dilakukan untuk mengetahui tegangan, arus dan frekuensi dari pemanas induksi. Pengujian ini dilakukan menggunakan alat ukur berupa multimeter yang berfungsi untuk mengukur tegangan listrik dari pemanas induksi lalu untuk mengukur arus listrik digunakan clamp meter dan untuk mengukur frekuensi yang dihasilkan dari pemanas induksi menggunakan osiloskop. Prosedur pengujian pemanas induksi untuk penelitian ini adalah sebagai berikut:

1. Persiapkan semua alat yang akan digunakan.

2. Siapkan pemanas induksi yang akan digunakan.

3. Siapkan material logam yang digunakan sebagai media uji.

4. Siapkan alat ukur temperatur (termometer inframerah).

5. Siapkan osiloskop, multimeter dan clamp meter.

6. Mengukur temperatur pertama logam sebelum dipanaskan.

7. Sambungkan pemanas induksi ke sumber arus listrik.

8. Lalu ukur tegangan dan arus input dan output dari pemanas induksi

9. Letakkan logam di dalam kumparan pemanas

10. Nyalakan pemanas induksi dan pastikan kipas pendingin menyala.

11. Ukur temperatur logam dan ukur frekuensi dari pemanas induksi tersebut.

12. Ukur tegangan dan arus pada pemanas induksi ketika ada beban (logam). 


\section{A. Pengukuran Tegangan}

Proses pengukuran tegangan dilakukan di input pemanas induksi dan output bagian kumparan pemanas dan dihasilkan nilai sebagai berikut.

Tabel 2 Pengukuran tegangan

\begin{tabular}{|c|c|c|}
\hline \multicolumn{3}{|c|}{ Tabel 2 Pengukuran tegangan } \\
\hline Tanpa beban & Input & Output \\
\hline Beban & 22.6 Volt & 18 Volt \\
\hline
\end{tabular}

\section{B. Pengukuran Arus}

Proses pengukuran arus listrik dilakukan di input pemanas induksi dan output bagian kumparan pemanas dan dihasilkan nilai sebagai berikut.

Tabel 3 Pengukuran arus

\begin{tabular}{|c|c|c|}
\multicolumn{3}{|c}{ Tabel 3 Pengukuran arus } \\
\hline & Input & Output \\
\hline Tanpa beban & $8.5 \mathrm{~A}$ & $4.6 \mathrm{~A}$ \\
\hline Beban & $12 \mathrm{~A}$ & $10 \mathrm{~A}$ \\
\hline
\end{tabular}

\section{Pengukuran Frekuensi}

Pengukuran menggunakan osiloskop dilakukan dua kali yaitu ketika tidak ada beban dan ketika ada beban. Pengukuran ini bertujuan untuk mengetahui apakah hasil gelombang yang dihasilkan dari pemanas induksi menghasilkan gelombang sinus atau tidak.

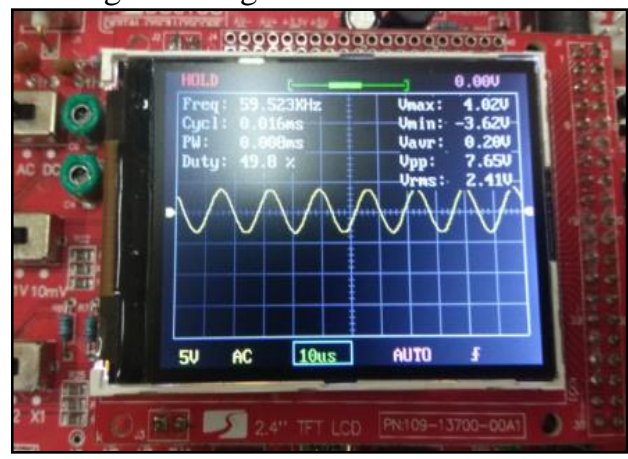

Gambar 14 Pengukuran frekuensi tampa beban

Pada gambar 14 tampilan di osiloskop menampilkan gelombang sinus yang dihasilkan oleh pemanas induksi dan menghasilkan frekuensi sebesar $59,5 \mathrm{kHz}$ ketika tidak ada beban.

Proses pengukuran frekuensi selanjutnya dilakukan menggunakan osiloskop ketika ada beban dan frekuensi terukur $61,7 \mathrm{kHz}$. Gelombang sinus yang dihasilkan terjadi penyimpangan bentuk yang diakibatkan oleh pembebanan dari logam uji .

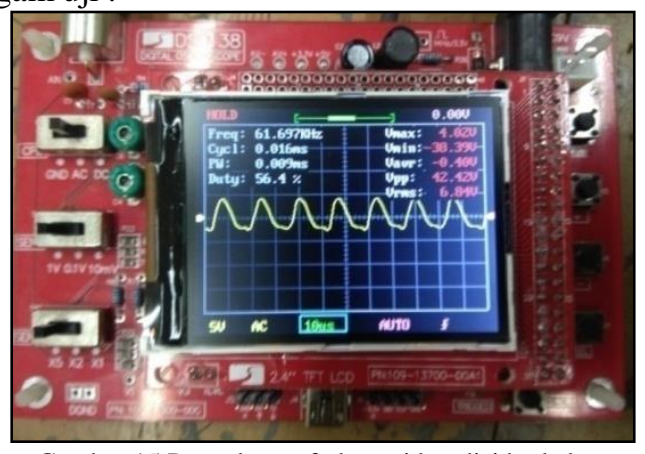

Gambar 15 Pengukuran frekuensi kondisi berbeban

\section{Pengukuran Temperatur}

Pengujian dilakukan untuk mengetahui kenaikan temperatur dari logam uji dan mengetahui temperatur maksimal yang bisa dicapai oleh pemanas induksi tersebut.

\begin{tabular}{|c|c|c|}
\multicolumn{3}{|c|}{ Tabel 4 Pengukuran temperatur } \\
\hline No & $\begin{array}{c}\text { Waktu } \\
\text { (menit) }\end{array}$ & $\begin{array}{c}\text { Temperatur } \\
\left({ }^{\circ} \mathbf{C}\right)\end{array}$ \\
\hline 1 & 0 & 28 \\
\hline 2 & 1 & 105 \\
\hline 3 & 2 & 235 \\
\hline 4 & 3 & 285 \\
\hline 5 & 4 & 334 \\
\hline 6 & 5 & 390 \\
\hline 7 & 6 & 421 \\
\hline 8 & 7 & 447 \\
\hline 9 & 8 & 458 \\
\hline 10 & 9 & 464 \\
\hline 11 & 10 & 465 \\
\hline
\end{tabular}

\section{Temuan Dan Pembahasan}

\begin{tabular}{|c|c|c|c|c|c|c|c|}
\hline No & $\begin{array}{l}\text { Waktu } \\
\text { (menit) }\end{array}$ & $\begin{array}{c}\text { Temperatur } \\
\left({ }^{\circ} \mathrm{C}\right)\end{array}$ & $\Delta t$ & $\begin{array}{c}\text { Kalor } \\
(\mathbf{J})\end{array}$ & $\begin{array}{l}\mathrm{Q} / \mathrm{s} \\
(\mathrm{W}) \\
\end{array}$ & $\begin{array}{c}\text { Daya } \\
(W)\end{array}$ & $\begin{array}{c}\text { Efesiens } \\
(\%)\end{array}$ \\
\hline 1 & 0 & 28 & 28 & 0 & 0 & 0 & 0 \\
\hline 2 & 60 & 105 & 77 & 2148.30 & 35.81 & 160.00 & 22.38 \\
\hline 3 & 120 & 235 & 207 & 5775.30 & 48.13 & 160.00 & 30.08 \\
\hline 4 & 180 & 285 & 257 & 7170.30 & 39.84 & 160.00 & 24.90 \\
\hline 5 & 240 & 334 & 306 & 8537.40 & 35.57 & 160.00 & 22.23 \\
\hline 6 & 300 & 390 & 362 & 10099.80 & 33.67 & 160.00 & 21.04 \\
\hline 7 & 360 & 421 & 393 & 10964.70 & 30.46 & 160.00 & 19.04 \\
\hline 8 & 420 & 447 & 419 & 11690.10 & 27.83 & 160.00 & 17.40 \\
\hline 9 & 480 & 458 & 430 & 11997.00 & 24.99 & 160.00 & 15.62 \\
\hline 10 & 540 & 464 & 436 & 12164.40 & 22.53 & 160.00 & 14.08 \\
\hline 11 & 600 & 465 & 437 & 12192.30 & 20.32 & 160.00 & 12.70 \\
\hline
\end{tabular}

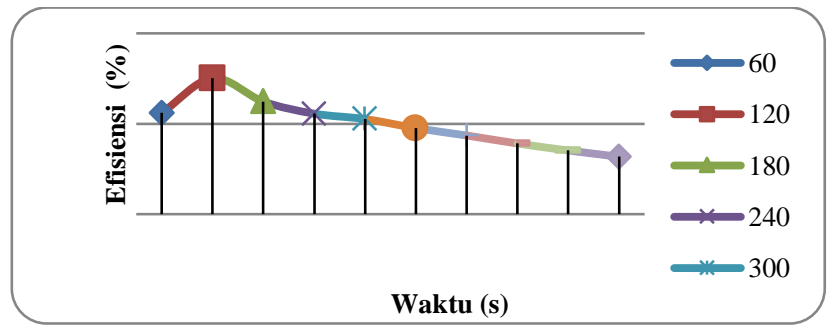

Gambar 16 Kurva karakteristik efisiensi tungku pemanas

Pada grafik di atas dapat dilihat efisiensi pemanasan tertinggi terjadi pada menit ke 2 yaitu sebesar $30.1 \%$ dan pada menit seterusnya nilai efisiensi semakin menurun dikarenakan pada proses pemanasan logam terjadi penurunan kecepatan pemanasan yang mengakibatkan efisiensi menurun hingga $12.7 \%$ pada menit ke10 setelah mulai pengujian, hal ini diakibatkan kenaikan suhu karena semakin tinggi suhu maka semakin banyak energi panas yang terbuang ke lingkungan sekitar yang suhunya lebih rendah. 


\section{Simpulan}

Kesimpulan dari penelitian pembuatan pemanas induksi sederhana adalah sebagai berikut :

1. Pemanas induksi dapat dibuat dari komponen yang banyak dijual bebas dan dapat berfungsi dengan baik

2. Efisiensi maksimum pemanas induksi sederhana sebesar $30,1 \%$ pada menit ke-2 . Pemanas dapat memanaskan logam hingga temperatur $465^{\circ} \mathrm{C}$ dengan kalor yang dihasilkan $12192.3 \mathrm{~J}$ dan efisiensi kalor terendah sebesar $12.7 \%$ pada menit ke-10.

3. Dari hasil pengukuran didapatkan spesifikasi pemanas induksi sederhana, sebagai berikut :

$\begin{array}{ll}\text { Daya listrik input } & : 270 \mathrm{~W} \\ \text { Tegangan } & : 22,5 \mathrm{~V} \\ \text { Arus } & : 12 \mathrm{~A} \\ \text { Frekuensi input } & : 50 \mathrm{~Hz} \\ \text { Daya listrik output } & : 160 \mathrm{~W} \\ \text { Tegangan } & : 16 \mathrm{~V} \\ \text { Arus } & : 10 \mathrm{~A} \\ \text { Frekuensi output } & : 61.7 \mathrm{kHz}\end{array}$

\section{Kepustakaan}

[1] ZUHAL. 1988. "Dasar Tenik Tenaga Listrik Dan Elektronika Daya" Jakarta: Gramedia Pustaka Utama

[2] Muljowidodo Kartidjo Indra Djodikudumo. 1996. "Mekatronika" HEDS ITB Jl. ganesa no.10 bandung.

[3] Sutrino. 1986. "Elektronika Teori Dan Penerapanya" ITB Jl. ganesa no. 10 bandung. 1986

[4] Ir. Syahbardia, MT "Dasar-Dasar Teknik Tenaga Listrik" materi perkuliahan teknik tenaga listerik.

[5] http://repository.usu.ac.id/bitstream/handle/

123456789/54341/Chapter\%20II.pdf? sequence=4\&isAllowed=y (diakses pada tanggal 11 juli 2017).

[6] http://smartchameleon.blogspot.co.id/201 3/10/induction-heaterpemanas-dengan-system.html (diakses pada tanggal 12 juli 2017).

[7] http://staff.uny.ac.id/sites/default/files/

Materi\%20Elektronika\%20Daya\%20(Inverter)_0.pdf (diakses pada tanggal 12 juli 2017).

[8] http://elektronika-dasar.web.id/mosfet-sebagai-saklar/ (diakses pada tanggal 23 september 2017).

[9] http://zonaelektro.net/resistor-karakteristik-nilai-dan-fungsinya/ (diakses pada tanggal 23 september 2017)

[10] http://www.fachrozya.com/2014/01/fungsi-jenis-jenis-danpengertian-dioda.html (diakses pada tanggal 23 september 2017)

[11] https://elektronikdot.blogspot.co.id/2015/ 09/fungsi-kapasitor-padarangkaian-elektronika.html (diakses pada tanggal 23 september 2017).

[12] http://teknikelektronika.com/pengertian-dan-fungsi-induktorbeserta-jenis-jenis-induktor/ (diakses pada tanggal 23 september 2017).

[13] http://www.informasi-pendidikan.com/2015/03 /pengertian-kalorkapasitas-kalor-dan.html (diakses pada tanggal 23 september 2017).

[14] http://fisikazone.com/kalor-jenis-dan-kapasitas-kalor (diakses pada tanggal 23 september 2017). 